\title{
Research on Node Connection Scheme of a New Type of Steel- Concrete Composite Structure
}

\author{
Hong Chen ${ }^{1 *}$ Wei Luo ${ }^{1}$ Fengbing Zhao ${ }^{2}$ Wei Lu ${ }^{1}$, Hao Peng ${ }^{1}$ \\ ${ }^{1}$ China Power Construction Group EAST CHINA SURVEY DESIGN \& Research Institute Co. Ltd. Hangzhou China 310014 \\ ${ }^{2}$ Civil Engineering College of Chongqing Jiaotong University Chongqing China 400074
}

\begin{abstract}
Based on the research and exploration of the construction process of the steel reinforced concrete composite structure, this paper summarizes a set of systematic improvement methods for the design and construction of the section steel concrete composite structure. This method first improves the construction method of node connection. Splicing plates are staggered at the beam end to reduce the number of bolts. The BIM technology is employed to build a three-dimensional model to optimize the construction layout of the core area of the steel composite structure. In addition, the precise positioning of beams, columns, splicing plates, stiffeners, bolts, and welds can be obtained in advance. Therefore, the whole process of visualized construction can be realized to reduce construction cost and improve construction efficiency.
\end{abstract}

\section{Introduction}

At present, the beam-column composite structure is a commonly used connection form in the current steel structure buildings [1-5]. The traditional construction methods of the steel reinforced concrete composite structure prefabricated steel columns and beams in the processing plant, and use high-strength bolts or welding to connect the steel beams together [6-10]. These methods require welding operations on site, which is prone to fire, and the construction speed is small. During the on-site construction, the existence of welds makes the composite structure poor in seismic performance and low structural ductility. It is often necessary to increase construction auxiliary processes or local strengthening members to meet the requirements of the overall strength and stiffness of the structure. As a result, it inevitably leads to a certain amount of waste of resources and extension of the construction period, contrary to the original intention of green building [11-14]. In this case, the cantilever beam steel reinforced concrete composite structure is widely used. The welding process at the construction site reduces the source of construction hazards and reduces the requirements of such structures. However, these methods have a large amount of bolt holes and weakened cross-sections with high technical requirements for the workers. It is difficult to meet the construction accuracy on the basis of no steel composite structure model to be processed. To this end, China Power Construction Group EAST CHINA SURVEY DESIGN \& Research Institute Co. Ltd. summed up a set of systematic improvement methods for the design and construction of the steel reinforced concrete composite structure based on the previous works. The achievements could effectively reduce construction difficulty and cost, shorten construction period, improve construction efficiency and material utilization, which also meet the structural safety and economic performance at the same time.

This article proposes an optimized and improved method on the basis of the connection scheme of the traditional steel-concrete composite structure. The method can realize the visualization of the whole process, reduce the construction cost, and improve the construction efficiency. The follow-up paper will introduce the proposed method in detail from several aspects such as principle, process and operation points, and provide guidance for subsequent specific use.

\section{Description of Principle and Characteristics}

Splicing plates are provided on the upper wing plate of the cantilever beam, the lower wing plate of the frame beam (or the lower wing plate of the cantilever beam and the upper wing plate of the frame beam) and the connection of the two splicing plates and the beam is welded in advance in the factory. In the construction of the beam-to-beam connection, the splicing board can simultaneously play the role of the ear board. Compared with the traditional method (shown in Figure 1), the improved construction method speeds up the positioning of the beam section. Based on the principle of jointreinforced plastic hinges moving outwards, adding horizontal and vertical stiffeners at the beam-column connection can increase the ductility of the composite structure and improve the seismic performance of the structure. The welding of steel columns and beams, steel

\footnotetext{
a Corresponding author: Hong Chen chen h7@hdec.com
} 
beams and splicing plates are all implemented in the processing plant, which can avoid the fire risk caused by on-site welding operations, reduce the technical difficulty of the construction site, and improve the construction efficiency. The BIM three-dimensional modeling technology can be used to optimize the construction layout of the core area of the steel composite structure node, which forms a preset model for the entire construction process. So, the visualization of the entire construction process can be realized to ensure the accuracy of structural installation and safety performance.

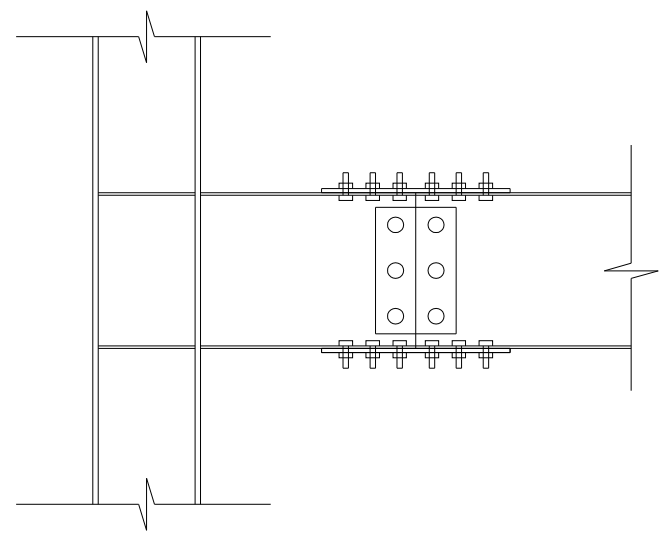

(a) View 1

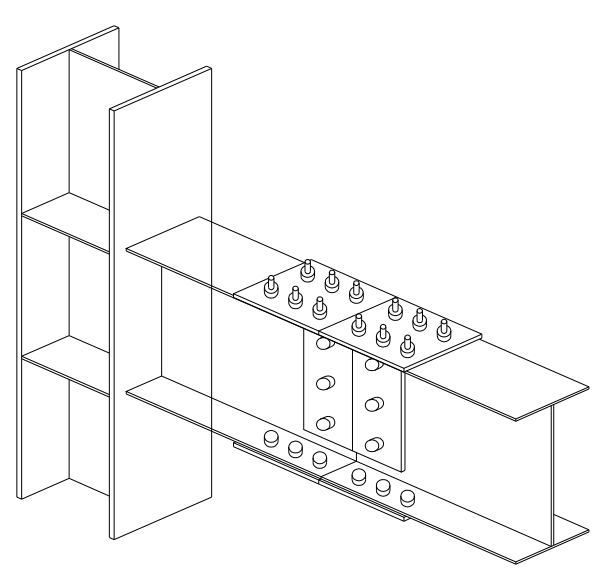

(b) View 2

Figure 1 Illustration of traditional node connection method

\section{Description of Construction}

\subsection{Construction process}

\subsubsection{Construction process of construction system}

The process can be summarized as following steps, shown in Figure 2.

Step 1: Determination of construction methods and construction principles;

Step 2: Creation of a profile steel composite model based on construction information and 3D model technology;
Step 3: Optimization of the design and construction parameters such as splicing plate size, stiffening plate position, bolt spacing, etc.;

Step 4: Map the optimized positioning information and design information to the steel reinforced concrete composite structure model;

Step 5: Process the steel reinforced column and spliced beam body with cantilever beam segments

Step 6: Connect cantilever beams and splicing beams according to the models and principle.

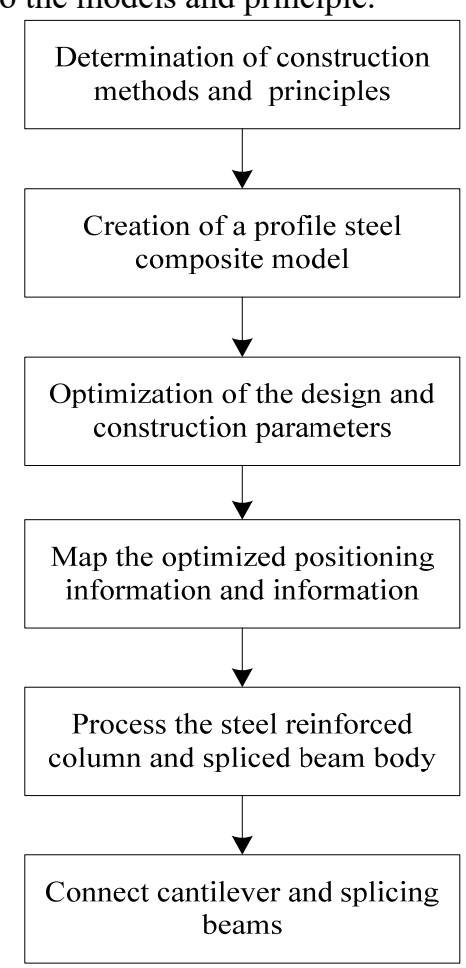

Figure 2 Procedure of building the construction system

\subsubsection{On-site construction process}

The process can be summarized as following steps, shown in Figure 3

Step 1: Construction preparation;

Step 2: Weld the upper (lower) splicing plate on the upper (lower) flange of the cantilever beam;

Step 3: Hoist the steel column with the cantilever beam section in place;

Step 4: Splice the plate under the lower (upper) flange of the splicing beam;

Step 5: Hoist the spliced beam in place;

Step 6: Connect the upper (lower) flange of the splicing beam with the upper (lower) splicing plate using bolts;

Step 7: Use bolts to connect the lower (upper) flange of the cantilever beam with the lower (upper) splicing plate;

Step 8: Splice the webs. 


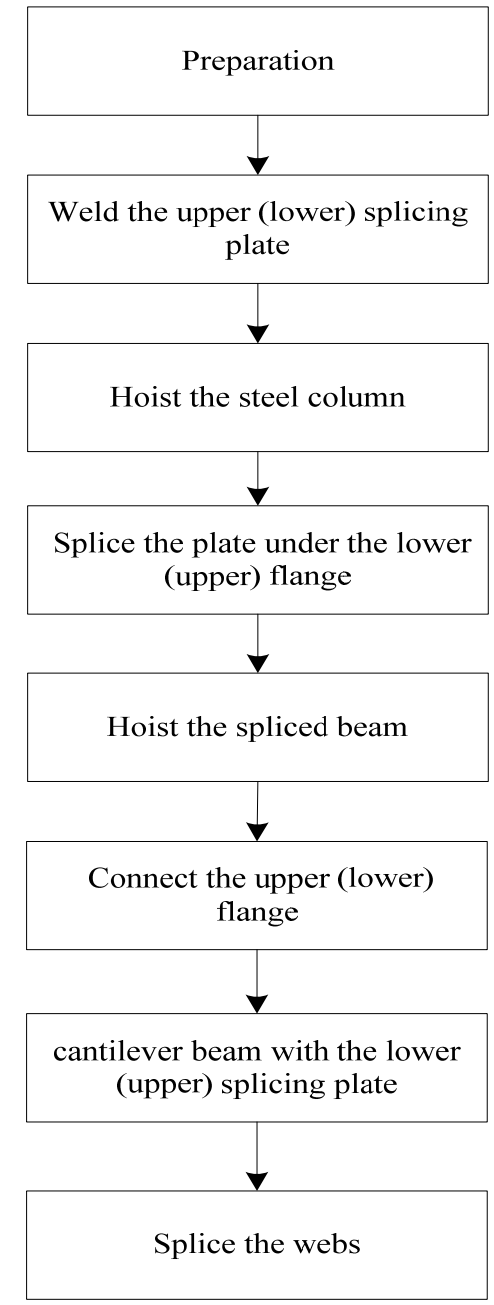

Figure 3 Procedure of building the on-site construction system

\subsection{Operation points}

Actually, there are many operating points during the construction process to make sure the final quality. Among all these factors, the following three, i.e., steel column hoisting, steel beam hoisting, and bolt construction, are the three major points as illustrated in Figure 4, which should be paid more attention on. In the followings, the three operation points are discussed in detail.

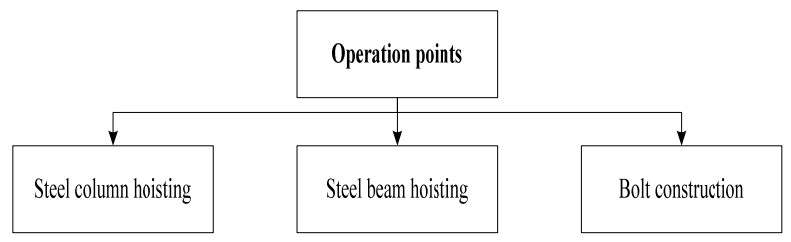

Figure 4 Major operatiion points during the construction process

\subsubsection{Steel column hoisting}

The location and number of lifting points should be determined according to the shape, end face, length, crane performance and other specific conditions of the steel column. In multi-storey and high-rise steel structure projects, steel columns are generally lifted by a single machine. For special or overweight components, two machines can also be used for lifting. There are three tasks for steel column correction: column elevation adjustment, column axis adjustment, and column verticality correction. During the entire construction process, the measurement should be the main focus.

\subsubsection{Steel beam hoisting}

Steel beam installation generally adopts tool-type lifting lugs or binding method for hoisting. Before installation, the center mark of the steel beam should be led to the end of the steel beam to facilitate temporary positioning according to the positioning axis of the column corbel during hoisting. Steel beam correction includes elevation adjustment, vertical / horizontal axis and verticality adjustment. The elevations of both sides of each beam are measured and all the data is weighted to calculate a standard value. The elevation adjustment value of each point is calculated according to the standard value. When the longitudinal and longitudinal axis errors of the steel beam meet the requirements, the frame beam span is rechecked. The hammer ball is hanged from the upper flange of the beam, and the horizontal distance from the string to the upper and lower parts of the beam web is measured. According to the inclination of the beam, the components are adjusted to ensure consistency.

\subsubsection{Bolt construction}

The node assembly needs to clean the friction surface. If the plate is not straight, it should be assembled after the straightness meets the requirements. Temporary bolts should be installed first when assembling steel components. Temporary bolts cannot be replaced by high-strength bolts. When a small number of holes are not correct and the displacement is small, punching nails can be used to drive in and locate, and then install the bolts. The penetration of high-strength bolts should be carried out after adjusting the center position of the structure and freely penetrate into the hole. The locations of the high-strength bolt washers should be consistent with attention on the front and back directions of the washers during installation. In addition, no shear should be allowed in the hole.

After all the large hexagon head high-strength bolts are installed in place, they can be tightened. The tightening method is generally carried out in two steps, namely, initial tightening and final tightening. The initial tightening torque should be $60 \%$ to $80 \%$ of the standard axial force, which should be properly controlled according to the steel plate thickness and bolt spacing. Considering the effects caused by the external environment, the initial screwing and final screwing should generally be completed within one day. The tightening of the torsion shear type high-strength bolts must also be carried out twice. The initial tightening is tightened to $60 \%$ to $80 \%$ of the standard axial force of the bolt. The second tightening is the final tightening, and the torsion shear type high-strength bolts should be 
screwed out of the torso clip head during the final tightening.

\section{Conclusion}

Based on the research and exploration of the construction process of the steel reinforced concrete composite structure, this paper systematically proposes a set of improvement methods for the design and construction of the section steel concrete composite structure. The improved construction method has been improved in terms of construction process and operating points. It is validated more suitable for contemporary architectural requirements, and can provide technical support for subsequent related needs. In the future, we will continue to optimize and upgrade the current node connection scheme, and continuously improve the operational convenience and overall building cost performance during the actual construction process, and further provide technical support for green buildings.

\section{Acknowledgement}

This work is supported by Research Project of China Power Construction Group East China Survey Design \& Research Institute Company Limited (KY2020-JG-3201-2021).

\section{References}

1. Spacone, E., and S. El-Tawil. "Nonlinear Analysis of Steel-Concrete Composite Structures: State of the Art." Journal of Structural Engineering 130. 2(2004): 159-168.

2. Sebastian, W. M., and R. E. Mcconnel. "Nonlinear FE Analysis of Steel-Concrete Composite Structures." Journal of Structural Engineering 126.6 (2000): 662-674.

3. Lin, J. P., J. F. Wang, and R. Q. Xu. "Cohesive Zone Model Based Numerical Analysis of SteelConcrete Composite Structure Push-Out Tests." Mathematical Problems in Engineering, 2014, (2014-7-3) 2014(2014): 1-12.

4. Kim, S. H., S. Park, and C. Y. Jung. "A New Type of Shear Connection System for Steel-concrete Composite Structures: Y-Type Perfobond Rib Shear Connector." Magazine of the Korea Concrete Institute (2015).

5. Xia, J., Z. Shen, and B. Chen. "Dynamic Analysis of Steel-Concrete Composite Frames with Partial Interaction." Advanced Materials Research 594597(2012):904-907.

6. Xian, L., et al. "Bolted end plate connections for steel reinforced concrete composite structures." Structural Engineering \& Mechanics 24.3(2006):291-306.

7. Zhou, Z. C., and H. G. Lei. "Seismic Analysis of a High Rise Antique-Style Pagoda with Steel
Reinforced Concrete Composite Structure." Applied Mechanics and Materials 851(2016):733-738.

8. Irino, T., et al. "Construction of Silo with Steel Lined Reinforced Concrete Composite Structure." Concrete Journal 27.8(1989):38-46.

9. Liu, S. L., Hao, P. L., \& Song, Y. X.. (2011). An exploration of establishment of green building evaluation standards weight system based on analytic hierarchy process. Applied Mechanics \& Materials, 71-78, 4166-4169.

10. Fan, B., \& Zhao, X. Y.. (2014). Comparing the core evaluation system for green building at home and broad. Applied Mechanics and Materials, 507, 163167.

11. Mao, D., Zhou, K., Zheng, S. J., Liu, Y. D., \& Liu, Y. P.. (2011). Research on evaluation system of green building in china. Advanced Materials Research, 224, 159-163.

12. Wang, Q., Feng, X. P., Tian, B., \& Li, C. T.. (2014). Study on the evaluation index system and evaluation method for the building energy-saving and green building demonstration zone. Advanced Materials Research, 962-965(12), 1612-1615.

13. Zhang, X., Zhan, C., Wang, X., \& Li, G.. (2019). Asian green building rating tools: a comparative study on scoring methods of quantitative evaluation systems. Journal of Cleaner Production, 218(MAY 1), 880-895.

14. Qi-Gan, S., James, L., Sung-Shun, W., \& YenChing, C.. (2018). Improving the green building evaluation system in china based on the danp method. Sustainability, 10(4), 1173. 